\title{
Painful Hashimoto Thyroiditis in a 7-Year-Old Girl: Differential Diagnosis and Medical Treatment
}

\author{
Gihong Park ${ }^{1}$, Kyungchul Song ${ }^{1}$, Hyun Joo Shin ${ }^{2}$ and Hyun Wook Chae ${ }^{1}$ \\ Department of Pediatrics, Severance Children's Hospital, Endocrine Research Institute, Yonsei University College of Medicine ${ }^{1}$, \\ Seoul, Department of Radiology, Research Institute of Radiological Science, Yongin Severance Hospital, Yonsei University College \\ of Medicine', Yongin, Korea
}

Painful Hashimoto thyroiditis (HT) is a rare pediatric condition. Because of the rarity of painful HT, it can be misdiagnosed as other thyroid diseases, and there is limited evidence regarding its clinical course and treatment. A 7-year-old girl presented to the emergency room with neck pain. A physical examination revealed diffusely enlarged thyroid gland with firm consistency and without tenderness. Her serum free thyroxine level was decreased and levels of thyroid-stimulating hormone, thyroglobulin antibody, and thyroid-stimulating antibody were elevated. The ultrasonography revealed a diffusely enlarged thyroid gland with homogeneously hypoechoic parenchyma and lobulated contours. She was diagnosed with painful HT based on the clinical presentations, laboratory tests, and ultrasonography findings, and was treated with a steroid, levothyroxine, and nonsteroidal anti-inflammatory drugs, after which her clinical symptoms improved dramatically. We should consider the possibility of painful HT in children with neck pain; HT could be treated with medical treatment.

Key Words: Hypothyroidism, Hashimoto disease, Neck pain, Goiter, Child

\section{Introduction}

Hashimoto thyroiditis $(\mathrm{HT})$, an autoimmune thyroid disorder, is the most common cause of acquired hypothyroidism in youth. ${ }^{1)}$ It predominantly affects individuals during the early to mid-puberty stages, and the patients with this disease usually develop a diffuse goiter without pain or tenderness. ${ }^{2,3)}$ Patients with HT exhibit various types of thyroid function-related manifestations, such as subclinical hypothyroidism, hypothyroidism, euthyroidism, or hyperthyroidism with elevated autoantibody levels. ${ }^{1,2)}$

Patients can present with symptoms, such as neck pain and tenderness, in very rare cases. ${ }^{3)}$ Due to the rarity of painful HT, it can be misdiagnosed as other thyroid diseases, such as subacute thyroiditis (SAT) or infection. Furthermore, there is limited evidence regarding the clinical course and appropriate treatment of this condition. ${ }^{3)}$

Therefore, here, we report a case involving a child with painful HT. A 7-year-old girl presented with a painful goiter and consequent neck swelling, which were present for 1 year, and the laboratory findings suggested a diagnosis of HT.

\section{Case Report}

A 7-year-old girl visited the emergency room with a chief complaint of pain in the anterior region of the

Received April 12, 2021 / Revised April 28, 2021 / Accepted April 28, 2021

Correspondence: Hyun Wook Chae, MD, PhD, Department of Pediatrics, Severance Children's Hospital, Endocrine Research Institute, Yonsei University College of Medicine, 50-1 Yonsei-ro, Seodaemun-gu, Seoul 03722, Korea

Tel: 82-2-2019-3350, Fax:82-2-393-9118, E-mail: hopechae@yuhs.ac

Copyright (c) the Korean Thyroid Association. All rights reserved.

(1) \& This is an open-access article distributed under the terms of the Creative Commons Attribution Non-Commercial License (http://creative(1) (1) \& commons.org/licenses/by-nc/4.0/), which permits unrestricted non-commercial use, distribution, and reproduction in any medium, provided the original work is properly cited. 
neck. The pain was not radiating in nature and was not aggravated by swallowing. This symptom was apparent for three days. She had a goiter for one year, although no prior evaluation had been performed. She had cold intolerance for 6 months, but oral intake was tolerable, and did not have chronic fatigue, swelling, or constipation. Her developmental status was normal, and she did not show any problems with social relationship, activity, or personality changes. She did not have any medical or treatment history, including immunosuppression, frequent infections, or any recent history of upper respiratory tract infection. Her father had type 2 diabetes and dyslipidemia. However, no one in her family had a history of thyroid disorders. She did not experience symptoms such as fever or headaches. She exhibited cold intolerance without weight change. Her vital signs were as follows: pulse rate, 90 beats/min; blood pressure, 105/68 $\mathrm{mmHg}$ (50-75th percentile); respiratory rate, 18 times/min; and body temperature, $37.0^{\circ} \mathrm{C}$. Physical examinations revealed that both her thyroid lobes were diffusely enlarged and were $5 \times 7 \mathrm{~cm}$ in size, with a firm consistency and without tenderness. No definitive nodule was palpable in either thyroid gland. Her anthropometric measurements were as follows: height, $133.2 \mathrm{~cm}$ (1.31 height standard deviation score [SDS]); weight, $25.6 \mathrm{~kg}$ ( -0.39 weight SDS); and body mass index, $23.04 \mathrm{~kg} / \mathrm{m}^{2}$ (14th percentile).

Complete blood counts, electrolyte levels, glucose levels, liver and renal function test results, erythrocyte sedimentation rate (ESR), and C-reactive protein (CRP) levels were normal. Her serum thyroid-stimulating hormone (TSH) level was elevated at 227.0 $\mu \mathrm{IU} / \mathrm{mL}$ (normal: $0.41-4.69 \mu \mathrm{lU} / \mathrm{mL}$ ), the free thyroxine (FT4) level was $0.23 \mathrm{ng} / \mathrm{dL}$ (normal: $0.8-1.7$ $\mathrm{ng} / \mathrm{dL}$ ), and the triiodothyronine level was $0.61 \mathrm{ng} / \mathrm{mL}$ (normal: $0.71-1.61 \mathrm{ng} / \mathrm{mL}$ ). Autoantibody levels were elevated as shown in Table 1. Thyroid ultrasonography (US) revealed a diffusely enlarged thyroid gland with homogeneously mild hypoechoic changes involving the entire area of both thyroid glands with lobulated contours (Fig. 1). Color Doppler US showed diffuse hypervascularity without hypovascular portion in the hypoechoic lesion. No cervical lymphadenopathy was detected. Oral prednisolone $\left(\right.$ Solondo $\left.{ }^{\circledR}\right) 0.9 \mathrm{mg} / \mathrm{kg} / \mathrm{d}$, levothyroxine (Synthyroxine ${ }^{\circledR}$ ) $3.9 \mathrm{mcg} / \mathrm{kg} / \mathrm{d}$, and ibuprofen (Brufen syrup for children ${ }^{\circledR}$ ) $18.8 \mathrm{mg} / \mathrm{kg} / \mathrm{d}$ were prescribed as the starting medical treatment dose (Table 1). The neck pain improved dramatically after 10 days of treatment, and the goiter size decreased gradually. At 2 weeks after the initial treatment, her serum TSH level decreased to $8.22 \mu \mathrm{IU} / \mathrm{mL}$ and the FT4 level was $2.33 \mathrm{ng} / \mathrm{dL}$ (Table 1). After improvement of the clinical symptoms, we stopped prednisolone and started oral hydrocortisone (Hysone ${ }^{\circledR}$ ) 9.7 $\mathrm{mg} / \mathrm{m}^{2} / \mathrm{d}$ divided into two doses because the cortisol level was not sufficient. Even after the steroid and levothyroxine was tapered gradually, she did not com-

Table 1. Thyroid function tests and thyroid autoantibodies in the patient

\begin{tabular}{|c|c|c|c|c|c|c|c|c|}
\hline & First visit & 2 weeks & 4 weeks & 6 weeks & 8 weeks & 10 weeks & 14 weeks & Unit (reference range) \\
\hline T3 & 0.61 & 0.60 & 0.66 & 1.13 & 1.25 & 1.53 & 1.70 & $\mathrm{ng} / \mathrm{mL}(0.71-1.61)$ \\
\hline FT4 & 0.23 & 2.33 & 1.94 & 1.82 & 1.70 & 1.68 & 1.57 & $\mathrm{ng} / \mathrm{dL}(0.8-1.7)$ \\
\hline $\mathrm{TSH}$ & 227.0 & 8.22 & 1.30 & 2.75 & 3.83 & 2.69 & 4.45 & $\mu \mathrm{IU} / \mathrm{mL}(0.41-4.69)$ \\
\hline TPO antibody & $<9$ & & & & & & & $\mathrm{IU} / \mathrm{mL}(0-34)$ \\
\hline $\begin{array}{l}\text { Thyroglobulin } \\
\text { antibody }\end{array}$ & 322.0 & & & & & & & $\mathrm{IU} / \mathrm{mL}(0-130.6)$ \\
\hline $\begin{array}{l}\text { TSH receptor } \\
\text { antibody }\end{array}$ & $<0.8$ & & & & & & & IU/L (0-1.75) \\
\hline $\begin{array}{l}\text { Thyroid stimulating } \\
\text { antibody }\end{array}$ & 198.4 & & & & & & & $\%(<140)$ \\
\hline Prednisolone* & 22.5 & 10 & 7.5 & 3.75 & Stop & & & $\mathrm{mg} / \mathrm{d}$ \\
\hline Hydrocortisone* & & & & & 10 & 10 & 10 & $\mathrm{mg} / \mathrm{d}$ \\
\hline
\end{tabular}

*Prescription of prednisolone and hydrocortisone was divided into two doses.

FT4: free thyroxine, T3: triiodothyronine, TPO: thyroperoxidase, TSH: thyroid-stimulating hormone 

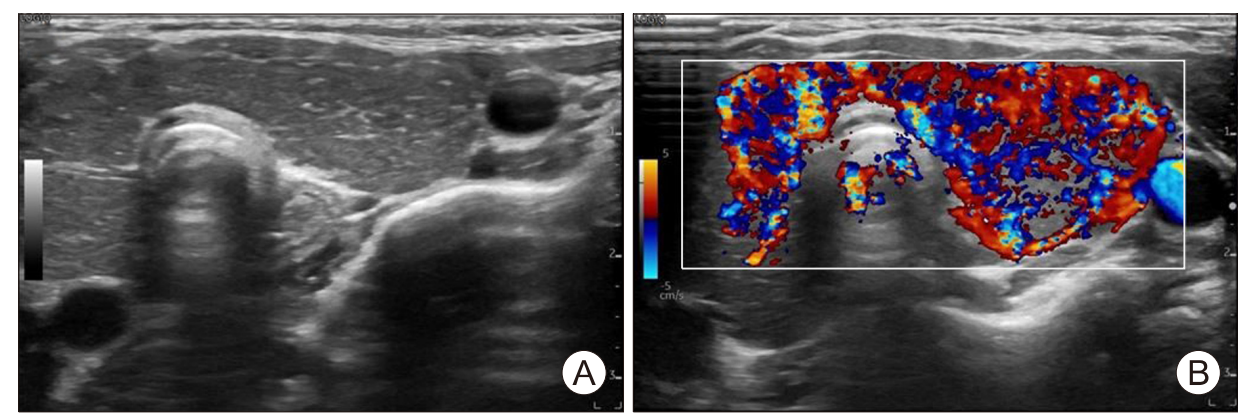

Fig. 1. Thyroid ultrasound images. (A) Ultrasonographic findings revealed a diffusely enlarged thyroid gland with homogeneously mild hypoechoic changes involving the entire area of both thyroid glands with lobulated contour. (B) Color Doppler ultrasonography showed diffuse hypervascularity without hypovascular portion in the hypoechoic lesion.

plain of neck pain again. At 14 weeks after initial treatment, her serum TSH level was $4.45 \mu \mathrm{IU} / \mathrm{mL}$ and the FT4 level was $1.57 \mathrm{ng} / \mathrm{dL}$, and the levothyroxine was stopped (Table 1).

\section{Discussion}

Our patient exhibited anterior neck pain and a goiter as a result of $\mathrm{HT}$, both of which improved dramatically following treatment with a steroid and levothyroxine. Although HT is the most common cause of acquired hypothyroidism in children, there are a very limited number of published reports regarding the clinical course and medical treatment of painful HT in children. ${ }^{1,3)}$

$H T$ is an autoimmune thyroid disorder induced by inflammation resulting from the infiltration of the thyroid gland by $B$ and $T$ cells that are reactive to thyroid antigens. ${ }^{4)}$ Patients with HT usually exhibit fatigue, weight gain, and myxoedema with a painless firm diffuse goiter. Laboratory findings often reveal hypothyroidism and the presence of autoantibodies to thyroglobulin and thyroid peroxidase. Thyroid stimulating $\mathrm{Ab}$, one of TSH receptor antibodies, stimulates TSH receptor through binding to leucine rich repeat region of the extracellular domain of the TSH receptor, and is associated with the risk of $H T^{5,6)}$ US usually reveals diffusely enlarged and hypoechoic thyroid gland with a heterogeneous echotexture and echogenic septations due to lymphocyte infiltration. The histology shows reactive lymphocytic infiltrations with occasional Hürthle cell changes and a few multinucleate histiocytes; however, a cytological analysis is not mandatory to reach a diagnosis because HT can be diagnosed based on laboratory findings indicating positive thyroperoxidase antibody and thyroglobulin antibody levels accompanied by abnormal thyroid function, an enlarged thyroid gland, and morphological changes on an US of the thyroid gland. ${ }^{2,7)}$ Thus, a biopsy was not performed on our patient because her clinical signs and symptoms, laboratory findings, and US findings were indicative of HT and because of the dramatic improvement observed in her symptoms and signs as a result of medical treatment.

Although most of the patients with HT do not have neck pain, HT can be a very rare cause of thyroid pain. ${ }^{2)}$ Patients with painful HT may have clinical manifestations including fever, thyroid pain, and tenderness, with elevated levels of white blood cell count, ESR, and CRP. ${ }^{2,8)}$ However, a significant number of patients do not have the clinical manifestations of inflammation such as fever or leukocytosis. Initial thyroid function may present as hypothyroidism, euthyroidism, and hyperthyroidism. Although a literature review reported statistical analysis for disease characteristics of painful HT in adults, a case report of the clinical course of painful HT in children is very limited. Because of its rarity, painful HT can be under-recognized in children with neck pain. Thus, investigations regarding clinical manifestations and laboratory tests of HT should be considered in children with neck pain without a definite diagnosis.

Among the causes of thyroid pain, SAT and infection are more common than $\mathrm{HT}^{3}{ }^{3)} \mathrm{SAT}$ is the most common 
reason for painful thyroiditis and is thought to be caused by viral infection. ${ }^{9)}$ Patients often develop SAT after acquiring an upper respiratory infection with fever. They complain of neck pain that radiates to the ear or jaws, which is aggravated by swallowing. A physical examination generally reveals a small diffuse goiter with tenderness. Laboratory findings reveal elevated ESR, CRP level, and leukocyte counts. On US, a thyroid gland affected by SAT has poorly defined hypoechoic avascular areas with a heterogeneous echo pattern in the acute phase, and the vascular flow increases slightly in the recovery phase. ${ }^{9,10)}$ The histology reveals intrafollicular cellular infiltration with the loss of colloid and destruction of the lining epithelium; however, a histologic examination is rarely required because SAT is usually diagnosed clinically. ${ }^{2,9)}$ Our patient exhibited neck pain; however, her past history, signs, and US findings were indicative of $\mathrm{HT}$ rather than SAT. Due to the rarity of painful HT, careful clinical approaches are required to differentiate painful HT from SAT in children with neck pain.

Significant numbers of patients underwent surgery due to poor response to medical treatment and high frequency of relapse in a literature review of adult painful HT. ${ }^{8)}$ Moreover, the number of thyroidectomies is increasing recently. Although oral medications cannot provide sustained pain resolution in adults generally, medical treatment with levothyroxine, steroid, and nonsteroidal anti-inflammatory drugs (NSAIDs) can be tried. In the case of hypothyroidism, levothyroxine can be effective for goiter shrinkage as well as for maintaining the euthyroid state. ${ }^{11)}$ The normalization of thyroid function has been found to occur in $16-50 \%$ of children with hypothyroidism resulting from HT. To treat the pain associated with HT in adults, oral prednisolone and NSAIDs, as well as levothyroxine, are recommended. However, a literature review of 70 cases of painful HT indicated that only $25-50 \%$ of patients experience pain relief with corticosteroid use. ${ }^{8)}$ NSAIDs failed to provide continuous pain control in most patients, and the sustained pain relief-related response rate with levothyroxine use in the absence of hypothyroidism was similar to that of oral corticosteroid use. Although studies involving the surgical treatment of painful HT in youth have been reported, a very limited number of elaborate studies involved an investigation into dosing strategies for the medication in children with painful $\mathrm{HT}^{3}{ }^{3)}$ Krakovitz et al. ${ }^{3)}$ reported five cases of youth with painful HT, and all of them were unable to resolve the pain with medical treatment and finally required surgical treatment. Our patient was treated with prednisolone $0.88 \mathrm{mg} / \mathrm{kg} / \mathrm{d}$, levothyroxine, and ibuprofen, and the pain and goiter size dramatically improved. Subsequently, the prednisolone and levothyroxine doses were gradually tapered.

In conclusion, we report a case involving a girl with painful thyroiditis that was effectively treated with medical treatment. Her neck pain improved dramatically with prednisolone, levothyroxine, and ibuprofen and did not worsen again even after the doses of the medications were tapered. Although painful HT is very rarely observed in children, it should be considered as one of the differential diagnoses in children with neck pain and goiter.

\section{Conflicts of Interest}

The authors declare that they have no conflict of interest.

\section{Ethical Approval}

Informed written consent was obtained from the patient for publication of this report and any accompanying images.

\section{Orcid}

Gihong Park: https://orcid.org/0000-0001-8423-0142 Kyungchul Song: https://orcid.org/0000-0002-8497-5934 Hyun Joo Shin: https://orcid.org/0000-0002-7462-2609 Hyun Wook Chae: https://orcid.org/0000-0001-5016-8539

\section{References}

1) Vukovic R, Zeljkovic A, Bufan B, Spasojevic-Kalimanovska V, Milenkovic T, Vekic J. Hashimoto thyroiditis and dyslipidemia 
in childhood: a review. Front Endocrinol (Lausanne) 2019;10: 868.

2) Seo HM, Kim M, Bae J, Kim JH, Lee JW, Lee SA, et al. A case of painful Hashimoto thyroiditis that mimicked subacute thyroiditis. Chonnam Med J 2012;48(1):69-72.

3) Krakovitz P, Cairns C, Schweiger BM, Burkey B. Surgical management of neck pain and headache associated with pediatric hashimoto's thyroiditis. Laryngoscope 2018;128(9):2213-7.

4) Anderson L, Middleton WD, Teefey SA, Reading CC, Langer JE, Desser T, et al. Hashimoto thyroiditis: Part 1, sonographic analysis of the nodular form of Hashimoto thyroiditis. AJR Am J Roentgenol 2010;195(1):208-15.

5) Kahaly GJ, Diana T, Glang J, Kanitz M, Pitz S, Konig J. Thyroid stimulating antibodies are highly prevalent in Hashimoto's thyroiditis and associated orbitopathy. J Clin Endocrinol Metab 2016;101(5):1998-2004.

6) Takasu N, Yamashiro K, Ochi Y, Sato Y, Nagata A, Komiya I, et al. TSBAb (TSH-stimulation blocking antibody) and TSAb (thyroid stimulating antibody) in TSBAb-positive patients with hypothyroidism and Graves' patients with hyperthyroidism. Horm Metab Res 2001;33(4):232-7.

7) Zdraveska N, Kocova M. Hashimoto thyroiditis in childhoodreview of the epidemiology, genetic susceptibility and clinical aspects of the disease. Maced J Med Sci 2012;5(3):336-45.

8) Peng CC, Huai-En Chang R, Pennant M, Huang HK, Munir KM. A literature review of painful Hashimoto thyroiditis: 70 published cases in the past 70 years. J Endocr Soc 2020;4(2): bvz008.

9) Lee MY, Lam WW, Wong WY. Subacute thyroiditis-an often overlooked sonographic diagnosis: report of 3 cases. I Ultrasound Med 2016;35(5):1095-100.

10) Park SY, Kim EK, Kim MJ, Kim BM, Oh KK, Hong SW, et al. Ultrasonographic characteristics of subacute granulomatous thyroiditis. Korean J Radiol 2006;7(4):229-34.

11) Admoni O, Rath S, Almagor T, Elias-Assad G, TenenbaumRakover Y. Long-term follow-up and outcomes of autoimmune thyroiditis in childhood. Front Endocrinol (Lausanne) 2020;11:309. 